\title{
Are public sector workers different? Cross-European evidence from elderly workers and retirees
}

\author{
Mirco Tonin ${ }^{1,2,3,4^{*}}$ and Michael Vlassopoulos ${ }^{1,4}$
}

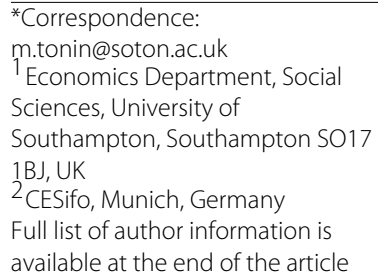

\begin{abstract}
We investigate whether public and private sector employees differ in terms of public service motivation using a representative sample of elderly workers from 12 European countries. We find that public sector workers, both those currently employed and those already retired, are significantly more prosocial; however, the difference in prosociality is explained by differences in the composition of the workforce across the two sectors, in terms of (former) workers' education and occupation. Subsample analysis reveals that public sector former workers in education are more prosocial even after controlling for a rich set of characteristics.
\end{abstract}

JEL codes: D64; H83; J45

Keywords: Public sector; Public service motivation; Volunteering

"Wall Street may be losing its luster for new U.S. college graduates who are increasingly looking to the government for jobs that enrich their social conscience, if not their wallet."

Wendell Marsh, Reuters, 11/06/2009.

\section{Introduction}

In most countries the public sector is a key economic actor, providing a wide range of goods and services, regulating the economic activities of firms and households, and redistributing large shares of national income through the tax and benefit system. To execute all these functions, the public sector employs a large fraction of the labor force: on average, government employment represents $15 \%$ of the labor force across the OECD, with compensation of government employees reaching 11\% of GDP (OECD 2011). Employees in the public sector operate in an environment where agency problems are arguably more severe than in the private sector (Dixit 2002; Besley and Ghatak 2003) due, for instance, to the multiplicity of objectives and principals characterizing public sector organizations and the difficulty in measuring output, which can give rise to phenomena such as corruption (Svensson 2005), regulatory capture (Dal Bo 2006), and waste (Bandiera et al. 2009). For these reasons, and given the importance of the tasks carried out in the public sector

(c) 2015 Tonin and Vlassopoulos; licensee Springer. This is an Open Access article distributed under the terms of the Creative Commons Attribution License (http://creativecommons.org/licenses/by/4.0), which permits unrestricted use, distribution, and reproduction in any medium, provided the original work is properly credited. 
(e.g. education, health care, law enforcement), understanding what are the characteristics of public sector employees is of primary importance. In particular, whether or not public sector workers are intrinsically motivated to carry out their job in order to serve the public interest, i.e., they have public service motivation, is important, for instance, for the design of remuneration policies (Besley and Ghatak 2005; Delfgaauw and Dur 2008; Dal Bo et al. 2013) and the outsourcing of public service provision to for-profit firms (Francois 2000; Francois and Vlassopoulos 2008) ${ }^{1}$. The issue of selection of workers into the public sector has also recently received a lot of attention in the development literature (Dal Bo et al. 2013; Hanna and Wang 2013; Banuri and Keefer 2013; Lagarde and Blaauw 2013; Ashraf et al. 2014).

In this paper, we assess whether the public sector is effective in attracting a particularly motivated workforce by comparing private and public sector workers, current and retired, along one aspect of prosocial behavior, namely, volunteering ${ }^{2}$. We draw data from the Survey of Health, Ageing and Retirement in Europe (SHARE), a representative crossnational survey of more than 85,000 individuals from 19 European countries aged 50 or over, with detailed information about health, socio-economic status and social and family networks. An important advantage of this dataset is that it allows us to compare not only current public and private sector employees but also retired workers from the two sectors. Moreover, we are able to follow a subsample of individuals who transition from employment into retirement and thus track how their behavior develops.

Looking at elderly workers and retirees, beyond being interesting in its own right because of ageing, represents the main methodological contribution of this paper. In what follows, we underline the advantages of using this demographic to identify public service motivation among public sector workers, while in the conclusions, we elaborate on some of its limitations. The first advantage of focusing on elderly workers is related to the fact that the early years of someone's career may not be very revealing in terms of tastes, as one may engage in "job hopping" in search of a good match (Jovanovic 1979). This problem is exacerbated if there is "queuing" for public sector jobs, as is common in many countries. Considering the latter part of one's career provides a better indication of preferences and, as the average job tenure in our sample of current employees is 21 years (while retirees have spent, on average, 25 years in their last job), we capture a sizeable part of the working life. Secondly, looking at retirees allows us to overcome two potential limitations associated with drawing inferences from samples of current workers, as the existing literature has done. The first is that the working environment is likely to be different between the private and public sectors in terms of working hours, job security, career incentives, required effort and so on, and it is difficult to control for all these differences. Thus, differences between current public and private sector employees may be due to (uncontrolled for) differences in the working environment rather than to differences in motivation. This is not an issue for retirees. The second limitation of comparing only current employees is that marginal and overall motivation may differ. Finding that, for instance, plumbers donate to charity more than nurses would indicate that their prosocial motivation is higher on the margin, but we could not infer how they compare in terms of overall motivation. Nurses may donate less because they have the opportunity to behave altruistically on the job and thus may feel less inclined to do it off the job. Of course, considerations about past contributions to society may play a role in the decision on whether or not to behave prosocially when retired, 
but we expect these to be of second order importance compared to contemporaneous events.

What we find is that public sector workers are more prosocially inclined as they are more likely to volunteer compared to private sector workers. In particular, working in the public sector increases the probability of volunteering by 3 percentage points compared to an average propensity to volunteer of $16 \%$. We also find that this difference in prosocial attitudes is mostly due to the composition of the public sector workforce. Indeed, once we control for factors like education and profession, there is no significant difference in the prosocial behavior of public and private sector employees. The results are similar when looking at retirees. In that sample, the unconditional difference is higher, $6 \%$, but is considerably reduced and becomes insignificant after controlling for personal characteristics. The longitudinal analysis, where we can control for individual fixed effects, reveals a positive shift in volunteering after retirement, but no differential shift depending on the sector of employment. This suggests that the two biases discussed above are either small or cancel each other out.

Thus, overall our results indicate that public sector workers are, on average, more prosocial than private sector workers, but this is mostly because they are, on average, more educated and less likely to perform menial tasks, factors that are positively correlated with prosociality. In other words, our results suggest that it is the structural difference of jobs in the public and private sector that explains the different prosocial attitudes of workers in the two sectors, while we do not find evidence of public service motivation that is specific to the public sector as a whole.

When we perform subgroup analysis on the more numerous sample of retirees, we find that, while public sector workers in education display significantly more prosocial motivation than comparable workers in the private sector, this is not the case for workers in health and social care, public administration and the rest of the public sector. When we narrow the comparison within broadly defined occupational groups, we do not find differences across the two sectors. For instance, we find that private and public sector managers and professionals are indistinguishable in terms of their prosocial motivation. We also find that public sector former workers with longer tenure in their last job are more prosocial, but this difference is not significant after controlling for personal characteristics. Finally, the pattern of findings regarding the public-private difference in prosociality outlined above - a significant premium in public sector in raw comparisons that vanishes when controlling for individual characteristics - is robust to considering different cohorts of retirees or different countries separately.

The rest of the paper is organized as follows. The next section discusses more in detail the relevant literature. Section 3 introduces the data and describes and provides summary statistics of the main variables. Section 4 presents the main results on differences in prosocial motivation. Section 5 conducts some subgroup analysis by industry, occupation, tenure, age group and country, while the last section concludes.

\section{Related literature}

Here, we briefly review the empirical literature concerning differences between public and private sector employees in terms of prosocial motivation. In the conclusions, we compare these findings to our results. 
Starting with studies that infer prosocial motivation from reported actions, Gregg et al. (2011) use the British Household Panel Survey and focus on individuals working in health, education, and social care industries. They find that employees in the non-profit sector are significantly more likely to do unpaid overtime than those in the for-profit sector; looking at the behavior of people who switch sectors, they find some supporting evidence that this is due to self-selection rather than to different institutional norms in the two sectors. There is also a literature in political science and public administration that explores empirically the issue of public sector motivation. Rotolo and Wilson (2006) and Lee (2012) use the Current Population Survey and find that public-sector workers are more likely to volunteer than private-sector ones. Brewer (2003) uses the American National Election Study and finds that government employees are more likely to participate in nonpolitical civic organizations and are more trustful than other citizens. Houston (2006) uses the General Social Survey and finds that public employees are more likely to volunteer and donate blood than private sector employees.

The study by Buurman et al. (2012) exploits a survey that took place in the Netherlands offering as a reward for completion a gift certificate, a lottery ticket, or a charitable donation. They look at whether public or private sector employees differ in their choices. What they find is that public sector employees are significantly less likely to choose the lottery. Moreover, public sector workers are more likely to choose the charity only at the start of their career, while, as tenure increases, the difference disappears and even reverses. By looking at whether people feel underpaid in their job, they also find some indication that public sector employees might not donate to the charity because they feel they have already contributed to society at work.

There are also several studies looking at reported motivations. Dur and Zoutenbier (2012) and Cowley and Smith (2014) use data from the World Values Survey to explore the importance of public sector mission in attracting motivated workers. The first paper finds an increase in the likelihood of working in the public sector for those workers who have both high altruism and confidence in political parties. The second paper finds that public sector workers exhibit higher intrinsic motivation in many countries and that the likelihood of intrinsically motivated workers to work in the public sector is negatively affected by corruption, with the effects being stronger for younger workers. Dur and Zoutenbier (2012) and Dohmen and Falk (2010) use data from the German Socio-Economic Panel Study. The first paper finds evidence of public sector workers being more altruistic (and lazy) than similar private sector employees, with the difference in altruism due to employees in caring industries and the difference in laziness due to workers with long experience, while the difference in altruism is not affected by experience. The second paper focuses on teachers and finds that they are more risk averse, trust more and are less negatively reciprocal than employees in other professions.

Recently, a series of papers in the development literature has looked at the issue of worker selection into the public sector. Dal Bo et al. (2013) use a field experiment in Mexico and find, among other things, that offering higher salaries at the recruitment stage attracts candidates with stronger public service motivation. Ashraf et al. (2014) set up a field experiment in Zambia and find that stressing the social dimension, rather than career perspectives, of public sector jobs does not affect the motivation of candidates. Hanna 
and Wang (2013) show evidence of negative selection into the public sector in India, with students more likely to cheat during a laboratory experiment also more likely to express a preference for a government job. Banuri and Keefer (2013), on the other hand, find evidence of positive selection into public service in Indonesia. Lastly, Lagarde and Blaauw (2013) report that nursing students in South Africa that displayed generous behavior in a dictator game with patient recipients, were more likely to then take up positions in rural areas, which are considered to be less desirable for health workers but more beneficial to the beneficiaries.

Finally, looking at senior citizens has been instrumental in addressing various important issues in economics. The SHARE dataset has been used, for instance, to look at portfolio choices (Christelis et al. 2010; 2013), the effect of retirement on cognitive abilities (Rohwedder and Willis 2010; Mazzonna and Peracchi 2012), the effects of education on the distribution of earnings (Brunello et al. 2009), the long term economic and health outcomes of exposure to war (Kesternich et al. 2012) and the prevalence of informal caregiving to elderly parents (Crespo and Mira 2014). There have also been studies, mostly in gerontology, describing the patterns of volunteering (see Hank and Erlinghagen 2010, for a review) or other outcomes among elderly people. To the best of our knowledge, this is, however, the first study looking at senior citizens, both working and retired, to uncover differences between the workforces in the public and private sectors.

\section{Data}

\subsection{The survey and samples}

We use data from waves 1 (2004), 2 (2006), and 4 (2011) of the Survey of Health, Ageing and Retirement in Europe (SHARE), which collects data on health, socio-economic status, social support and networks of a representative sample of individuals aged 50 and above from 19 European countries (plus Israel). Extensive documentation about the survey can be found at http://www.share-project.org/ ${ }^{3}$. We focus on 12 Western European countries (Austria, Germany, Sweden, the Netherlands, Spain, Italy, France, Denmark, Greece, Switzerland, Belgium, Portugal $)^{4}$.

We form two main samples: one of current employees and one of former employees who are currently retired. In both cases we restrict attention to individuals aged between 50 and 80 who were born in the country they are interviewed and exclude the self-employed. This leaves us with 12,165 observations for current employees and 19,486 observations for retirees, for which we have information for the control variables as well. In SHARE, some people are interviewed in multiple waves, but in creating the two main samples, we use just one observation per individual. For the employees sample, we select the one corresponding to the last occasion in which we observe the individual as an employee, while for the retirees sample, we select the first occasion in which we observe the individual as a retiree. Finally, we also construct a longitudinal sample consisting of the 1,800 individuals that we observe both as employees and as retirees. These individuals are in both the main samples.

\subsection{Key variables}

The key variable we use in our empirical analysis is sector of employment. This allows us to distinguish between private and public sector (former) employees. For 
the retirees sample, we derive the variable from the following two questions in the survey:

1. "We are now going to talk about the last job you had. In this job were you an employee or self-employed?" (Employee/ Civil servant/ Self-employed)

2. (If Employee) "In this job were you employed in the public sector?" (Yes/No)

For the employee sample, the questions are similar but refer to the current main job. We classify as public sector employees those answering "Civil servant" to the first question or "Employee" to the first question and "Yes" to the second question, and as private sector employees those answering "No" to the second question. We do not know in which sector individuals in our sample started their career or whether they have switched sectors during their working life. Nonetheless, as mentioned in the introduction, it may be preferable to consider the latter part of someone's working life, and in our sample, on average, employees have spent 21 years in their current job and retirees 25 years in their last job.

Our main outcome variable is prosociality. We classify as being prosocial those answering positively to a question on whether they had done voluntary or charity work in the last month ${ }^{5}$.

We also use information about other variables that may influence the likelihood of engaging in voluntary work like gender, marital status, age, education, health status, settlement type, household income, occupation, and participation in a sport, social, or other kind of club $^{6}$. For current employees, we also use information on characteristics of their working life that may have an impact on the propensity to volunteer, like the hours worked per week, whether they experience time pressure due to heavy workload, and whether they consider their salary adequate.

\subsection{Descriptive statistics}

Table 1 provides descriptive statistics on the size of the two samples in each country, ranging from 290 to 1551 individuals for employees and from 689 to 2814 for retirees, and the proportion of each country after applying survey weights. There is also information on the size of the public sector in terms of employment and the prevalence of prosocial

Table 1 Summary statistics

\begin{tabular}{|c|c|c|c|c|c|c|c|c|}
\hline \multirow{2}{*}{ Country } & \multicolumn{4}{|c|}{ Workers } & \multicolumn{4}{|c|}{ Retirees } \\
\hline & $\begin{array}{l}\text { Number } \\
\text { of obs. }\end{array}$ & $\begin{array}{l}\text { Weighted } \\
\text { proportion }\end{array}$ & $\begin{array}{l}\text { Public } \\
\text { sector (\%) }\end{array}$ & Prosocial (\%) & $\begin{array}{l}\text { Number } \\
\text { of obs. }\end{array}$ & $\begin{array}{l}\text { Weighted } \\
\text { proportion }\end{array}$ & $\begin{array}{l}\text { Public } \\
\text { sector (\%) }\end{array}$ & Prosocial (\%) \\
\hline Austria & 902 & 1.9 & 41.3 & 15.2 & 2814 & 3.3 & 33.3 & 13.9 \\
\hline Germany & 887 & 33.0 & 28.3 & 15.4 & 1522 & 25.0 & 26.9 & 15.2 \\
\hline Sweden & 1232 & 4.3 & 51.5 & 15.8 & 1717 & 2.7 & 53.7 & 20.8 \\
\hline Netherlands & 1242 & 5.8 & 53.6 & 28.2 & 1447 & 3.9 & 51.5 & 31.7 \\
\hline Spain & 758 & 10.9 & 39.0 & 6.8 & 1276 & 12.0 & 23.0 & 4.0 \\
\hline Italy & 818 & 15.0 & 44.8 & 12.4 & 1965 & 24.4 & 32.6 & 13.1 \\
\hline France & 1463 & 18.8 & 38.5 & 19.6 & 2465 & 17.7 & 38.6 & 22.0 \\
\hline Denmark & 1369 & 2.5 & 50.4 & 23.4 & 1229 & 1.8 & 51.1 & 22.4 \\
\hline Greece & 495 & 1.3 & 45.4 & 3.5 & 689 & 1.5 & 38.8 & 3.2 \\
\hline Switzerland & 1158 & 2.5 & 39.3 & 22.5 & 1168 & 2.0 & 38.9 & 22.7 \\
\hline Belgium & 1551 & 3.0 & 42.3 & 18.4 & 2382 & 3.7 & 40.3 & 23.8 \\
\hline Portugal & 290 & 1.1 & 44.6 & 5.3 & 812 & 2.1 & 43.3 & 6.8 \\
\hline Total & 12,165 & 100.0 & 38.2 & 15.8 & 19,486 & 100.0 & 33.5 & 15.5 \\
\hline
\end{tabular}


motivation, separately for each of the 12 countries in our sample. The public sector is substantial in size in the sample, averaging $38 \%$ in the employees sample and $34 \%$ in the retirees sample. The average measure of prosociality is around $16 \%$ in both samples, with significant variation across countries. The overall pattern is for countries in the South (Greece, Spain and Portugal) to score low on this measure and countries in Central and Northern Europe to display larger incidence of volunteering.

Table 2 reports means of our measure of prosociality for the whole population and across the two sectors as well as the demographic, socio-economic and health characteristics we use as controls in the regression analysis below. In terms of a rough comparison across sectors, the prevalence of prosocial motivation is higher among public sector current or former employees. Something to notice here, however, is that in both samples, individuals that retire from the private and public sector differ along important dimensions, most notably education and profession. In particular, there is a larger concentration of public sector workers who have completed some level of tertiary education, as compared to workers in the private sector, where there is a larger concentration of workers who have just completed primary education. With regards to occupation, again we see some marked differences across the two sectors that reflect the structural difference between what is produced in the two sectors. The public sector employs a higher proportion of white collar workers (managers, professionals, and clerks), while the private sector has a larger concentration of blue collar workers, both skilled and unskilled, and workers performing elementary jobs ${ }^{7}$. Comparing workers to retirees, it is not surprising that retirees are, on average, older and report experiencing health issues more frequently than current workers. Moreover, their household income is lower. It is also possible to notice that workers achieve a higher educational level compared to retirees, consistent with a secular increase in schooling. In line with this, the distribution of occupations for workers is skewed towards more skilled jobs compared to retirees.

\section{Main results}

Our main analysis involves estimating logit regressions of the following form:

$$
\text { Prosocial }_{i}=\alpha+\beta \text { Public }_{i}+X_{i}^{\prime} \delta+\mu_{c}+s_{t}+\epsilon_{i},
$$

where Prosocial $_{i}$ is a binary variable indicating whether individual $i$ has done any voluntary work, Public $i$ is a binary variable indicating whether an individual's current job is in the public sector or, for retirees, whether the last job before retirement was in the public sector, $X_{i}$ includes a set of individual socio-economic, demographic, job and health characteristics that we control for (summarized in Table 2), $\mu_{c}$ are country dummies, and $s_{t}$ are survey wave dummies. We use survey weights throughout and report average marginal effects and the associated standard errors obtained by using the delta method ${ }^{8}$.

\subsection{Baseline results}

Table 3 reports our baseline estimates of Equation 1, with and without controls. Looking first at the sample of workers, we find that the marginal effect of being employed in the public sector on the probability of undertaking voluntary work is $3.3 \%$ and is statistically significant. For retirees, the corresponding figure is $6.3 \%$, again statistically significant ${ }^{9}$. We saw earlier in Table 1 that on average the probability of voluntary activity in both samples is $16 \%$, so these figures indicate a rather large effect. However, when we 
Table 2 Demographic, socio-economic and health characteristics

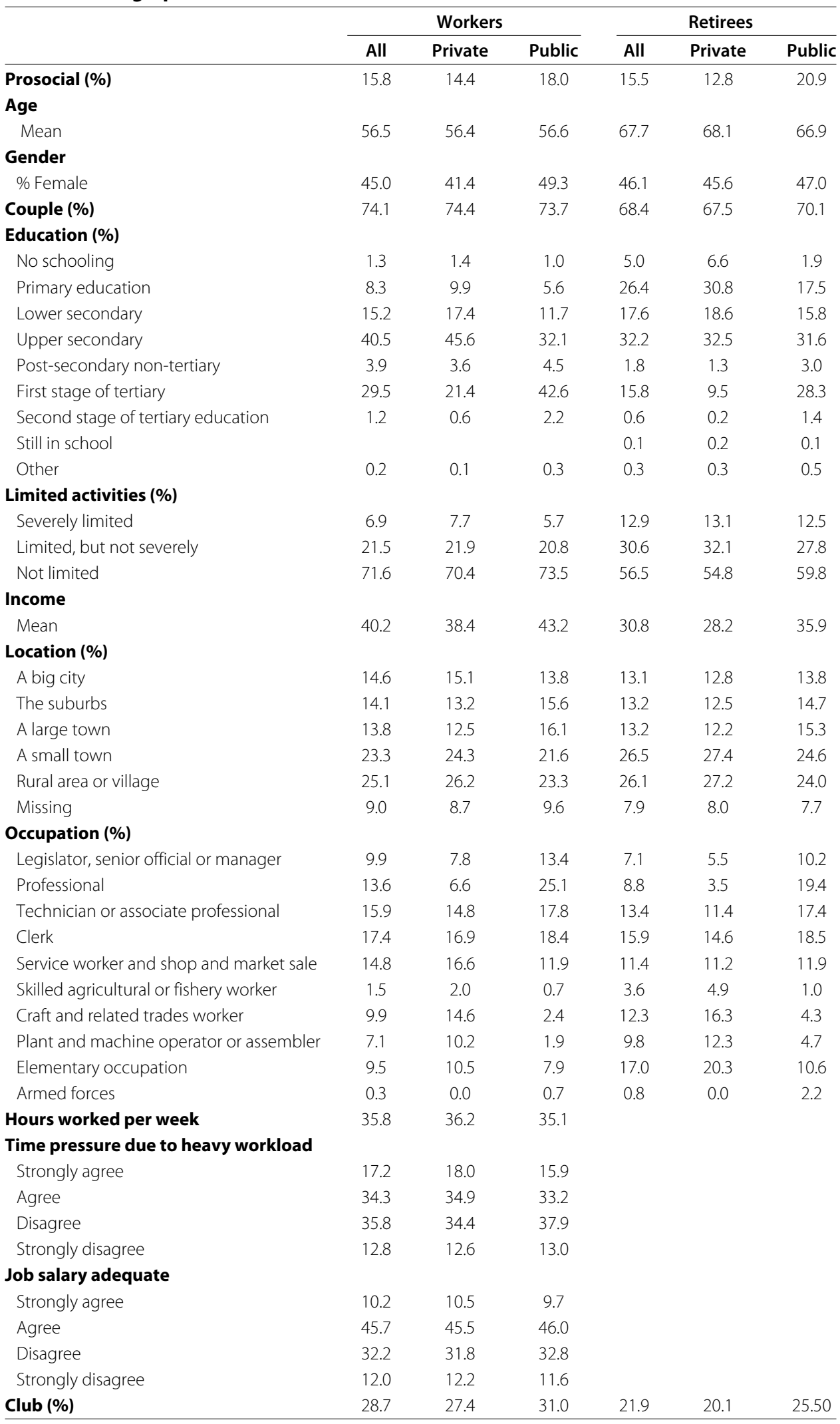

For workers, there are statistically significant differences across the two sectors in all of the characteristics, with the exception of age, couple, limited activities, time pressure and job salary adequate. For retirees, the only exception is gender. Income is in 1,000 euros 2007 Germany PPP. 
Table 3 Cross country logit regressions - marginal effects

\begin{tabular}{|c|c|c|c|c|}
\hline & \multicolumn{2}{|c|}{ Workers } & \multicolumn{2}{|c|}{ Retirees } \\
\hline & (1) & (2) & (3) & (4) \\
\hline Public & $0.033^{* *}$ & 0.002 & $0.063^{* * *}$ & 0.013 \\
\hline Male & & $0.032^{* *}$ & & -0.004 \\
\hline Couple & & -0.001 & & -0.001 \\
\hline Age & & 0.000 & & $-0.002^{* *}$ \\
\hline \multicolumn{5}{|l|}{ Education } \\
\hline Primary education & & -0.003 & & -0.003 \\
\hline Lower secondary & & 0.023 & & $0.050^{*}$ \\
\hline Upper secondary & & 0.017 & & 0.037 \\
\hline Post-secondary non-tertiary & & $0.134^{*}$ & & $0.111^{* * *}$ \\
\hline First stage of tertiary & & 0.070 & & $0.083^{* * *}$ \\
\hline Second stage of tertiary education & & 0.064 & & 0.065 \\
\hline Still in school & & 0 & & $-0.104^{* * *}$ \\
\hline Other & & -0.013 & & $0.096^{*}$ \\
\hline \multicolumn{5}{|l|}{ Limited Activities } \\
\hline Limited, but not severely & & -0.014 & & $0.037^{* * *}$ \\
\hline Not limited & & 0.003 & & $0.047^{* * *}$ \\
\hline \multicolumn{5}{|l|}{ Location } \\
\hline The suburbs & & 0.013 & & -0.029 \\
\hline A large town & & $0.048^{*}$ & & -0.013 \\
\hline A small town & & $0.050^{* *}$ & & 0.002 \\
\hline Rural area or village & & $0.069^{* * *}$ & & -0.001 \\
\hline Missing & & 0.019 & & -0.026 \\
\hline Income & & 0.000 & & 0.000 \\
\hline \multicolumn{5}{|l|}{ Occupation } \\
\hline Professional & & 0.022 & & 0.003 \\
\hline Technician or associate professional & & -0.001 & & -0.012 \\
\hline Clerk & & -0.028 & & -0.029 \\
\hline Service worker and shop and market sale & & -0.021 & & $-0.034^{*}$ \\
\hline Skilled agricultural or fishery worker & & -0.045 & & $-0.123^{* * *}$ \\
\hline Craft and related trades worker & & -0.059 & & $-0.084^{* * *}$ \\
\hline Plant and machine operator or assembler & & $-0.079 * *$ & & $-0.060^{* * *}$ \\
\hline Elementary occupation & & -0.040 & & $-0.066^{* * *}$ \\
\hline Armed forces & & -0.071 & & 0.052 \\
\hline Hours Worked per Week & & $-0.001^{*}$ & & \\
\hline \multicolumn{5}{|l|}{ Time Pressure due to Heavy Workload } \\
\hline Agree & & 0.015 & & \\
\hline Disagree & & 0.012 & & \\
\hline Strongly disagree & & -0.012 & & \\
\hline \multicolumn{5}{|l|}{ Job Salary Adequate } \\
\hline Agree & & 0.002 & & \\
\hline Disagree & & -0.014 & & \\
\hline Strongly disagree & & 0.025 & & \\
\hline Club & & $0.101^{* * *}$ & & $0.11^{* * *}$ \\
\hline $\mathrm{N}$ & 12165 & 12165 & 19486 & 19486 \\
\hline
\end{tabular}

Notes: Regressions include country and survey wave dummies.

${ }_{* * *}^{* * *}\left(^{*}\right)$ denote significance at $1,[5],(10) \%$ level.

Omitted categories are: education (none), limited activities (severely limited), type of settlement (big city), occupation (Managers). 
account for the various individual controls, the marginal effect of public sector experience drops in the two samples to $0.2 \%$ and $1.3 \%$, respectively, and is in both cases statistically insignificant.

Regarding the marginal effects of the other covariates in the estimated regression, we see some evidence that among retirees, more educated individuals and those who do not suffer from health problems that limit their activities are significantly more likely to volunteer. Among the various occupations, there is evidence of a negative association between the propensity to volunteer and jobs in agriculture, crafts and trade, and elementary occupations. In the employees sample, gender and location seem to matter, with males and those living in smaller communities more likely to volunteer. Note that to account for possible differences in the availability of time or general propensity to have an active life, we also have a control for whether an individual reports having gone to a sport, social or other kind of club, and in both samples, we find a strong, positive association between voluntary work and engagement in this other type of social activity.

Summarizing, at first look, it appears that while individuals in the public sector are more prosocial, this difference is explained by personal characteristics. Once these differences in the composition of the respective workforces are accounted for, we find no evidence of any residual difference in prosociality between workers in the two sectors. In other words, we find no evidence of prosocial motivation that is specific to having a publicsector employer. This is true both when looking at current employees and at retirees.

\subsection{Analysis of explanatory power of characteristics}

In this section, we investigate which of the characteristics that we control for in the baseline regressions reported above are primarily responsible for the reduction of the public-private gap in volunteering that we see in Table 3. Our approach is to reestimate Equation 1 including only one (or two) additional characteristics as control(s) at a time. The outcome of this analysis is summarized in Table 4 for the sample of employees, which reports the marginal effect of having public sector experience, with each column of the table indicating the control variable included in the regression. What this analysis suggests is that only two characteristics, education (column 4) and occupation (column 8), have a substantial impact on the magnitude of the public sector marginal effect, reducing it to a value close to zero and rendering it statistically insignificant.

In Table 5, we report the results for the sample of retirees, controlling in this case also for combinations of two variables. In particular, the diagonal terms of the table correspond to regressions with one additional control, while the off diagonal terms contain marginal effects of regressions with combinations of controls indicated by the corresponding row and column heading. Focusing first on the diagonal terms, what this analysis suggests is

Table 4 Cross country logit regressions - marginal effects - workers

\begin{tabular}{cccccccccc}
\hline $\begin{array}{c}\text { Male } \\
\text { (1) }\end{array}$ & $\begin{array}{c}\text { Couple } \\
\text { (2) }\end{array}$ & $\begin{array}{c}\text { Age } \\
\text { (3) }\end{array}$ & $\begin{array}{c}\text { Education } \\
\text { (4) }\end{array}$ & $\mathbf{( 5 )}$ & $\mathbf{( 6 )}$ & $\mathbf{( 7 )}$ & $\mathbf{( 8 )}$ & $\mathbf{( 9 )}$ & $\mathbf{( 1 0 )}$ \\
\hline $0.036^{* *}$ & $0.033^{* *}$ & $0.034^{* *}$ & 0.011 & $0.033^{* *}$ & $0.034^{* *}$ & $0.031^{*}$ & 0.007 & $0.029^{*}$ & $0.033^{* *}$ \\
$(0.016)$ & $(0.016)$ & $(0.016)$ & $(0.015)$ & $(0.016)$ & $(0.016)$ & $(0.016)$ & $(0.015)$ & $(0.016)$ & $(0.016)$ \\
\hline
\end{tabular}

Notes: The heading of each row indicate the control variable used in the regression. All columns include country and survey wave dummies.

In all columns, the number of observations is 12,165 .

The entries are average marginal effects standard errors are reported in parentheses.

***) denote significance at $5,(10) \%$ level. 
Table 5 Cross country logit regressions - marginal effects - retirees

\begin{tabular}{|c|c|c|c|c|c|c|c|c|c|}
\hline & Male & Couple & Age & Education & Limited activities & Location & Income & Occupation & Club \\
\hline & (1) & (2) & (3) & (4) & (5) & (6) & (7) & (8) & (9) \\
\hline \multirow[t]{2}{*}{ Male } & $0.063^{* * *}$ & $0.062^{* * *}$ & $0.059 * * *$ & $0.031^{* * *}$ & $0.061^{* * *}$ & $0.063^{* * *}$ & $0.058^{* * *}$ & $0.023^{* *}$ & $0.057^{* * *}$ \\
\hline & $(0.010)$ & $(0.010)$ & $(0.010)$ & $(0.010)$ & $(0.010)$ & $(0.010)$ & $(0.010)$ & $(0.010)$ & $(0.010)$ \\
\hline \multirow[t]{2}{*}{ Couple } & & $0.062^{* * *}$ & $0.058^{* * *}$ & $0.030 * * *$ & $0.061^{* * *}$ & $0.062^{* * *}$ & $0.059^{* * *}$ & $0.021^{* *}$ & $0.056^{* * *}$ \\
\hline & & $(0.010)$ & $(0.010)$ & $(0.010)$ & $(0.010)$ & $(0.010)$ & $(0.010)$ & $(0.010)$ & $(0.010)$ \\
\hline \multirow[t]{2}{*}{ Age } & & & $0.058^{* * *}$ & $0.030^{* * *}$ & $0.057^{* * *}$ & $0.058^{* * *}$ & $0.056^{* * *}$ & $0.020^{* *}$ & $0.053^{* * *}$ \\
\hline & & & $(0.010)$ & $(0.010)$ & $(0.010)$ & $(0.010)$ & $(0.010)$ & $(0.010)$ & $(0.010)$ \\
\hline \multirow[t]{2}{*}{ Education } & & & & $0.030^{* * *}$ & $0.030^{* * *}$ & $0.030^{* * *}$ & $0.030^{* * *}$ & 0.014 & $0.028^{* * *}$ \\
\hline & & & & $(0.010)$ & $(0.010)$ & $(0.010)$ & $(0.009)$ & $(0.009)$ & $(0.010)$ \\
\hline \multirow{2}{*}{$\begin{array}{l}\text { Limited } \\
\text { activities }\end{array}$} & & & & & $0.061^{* * *}$ & $0.061^{* * *}$ & $0.058^{* * *}$ & $0.021^{* *}$ & $0.055^{* * *}$ \\
\hline & & & & & $(0.010)$ & $(0.010)$ & $(0.010)$ & $(0.010)$ & $(0.010)$ \\
\hline \multirow[t]{2}{*}{ Location } & & & & & & $0.062^{* * *}$ & $0.059^{* * *}$ & $0.021^{* *}$ & $0.056^{* * *}$ \\
\hline & & & & & & $(0.010)$ & $(0.010)$ & $(0.010)$ & $(0.010)$ \\
\hline \multirow[t]{2}{*}{ Income } & & & & & & & $0.059^{* * *}$ & $0.021^{* *}$ & $0.053^{* * *}$ \\
\hline & & & & & & & $(0.010)$ & $(0.009)$ & $(0.009)$ \\
\hline \multirow[t]{2}{*}{ Occupation } & & & & & & & & $0.021^{* *}$ & $0.020^{* *}$ \\
\hline & & & & & & & & $(0.009)$ & $(0.009)$ \\
\hline \multirow[t]{2}{*}{ Club } & & & & & & & & & $0.056^{* * *}$ \\
\hline & & & & & & & & & $(0.010)$ \\
\hline
\end{tabular}

Notes: The heading(s) of each row and column indicate(s) the control variable(s) used in the regression. All columns include country and survey wave dummies.

In all columns, the number of observations is 19,486 .

The entries are average marginal effects; standard errors are reported in parentheses.

*** $\left.{ }^{* *}\right)$ denote significance at $1,(5) \%$ level.

that, again, only two characteristics, education (column 4) and occupation (column 8), have a substantial impact on the magnitude of the public sector marginal effect, reducing it by more than half. The rest of the individual characteristics on their own, including health status and club participation, have no noticeable impact on the magnitude and significance of the marginal effect of the public sector dummy compared to what we obtain in the unconditional regression in Table 3. Turning attention to the off diagonal terms, we find that when we introduce characteristics in pairs, the public-private difference in the likelihood of volunteering is reduced only when either education or occupation is present and that no other characteristic is able to further reduce the marginal effect when combined with either of these two controls. Finally, when we introduce education and occupation simultaneously, the marginal effect shrinks to $1.4 \%$ and is statistically insignificant (row 4, column 8), thus closely resembling the outcome in Table 3 when including all controls.

These results indicate that the estimated raw difference in prosocial activity across individuals from the private and public sector is not due to differences in time availability or health status, but rather to the fact that the public sector employs more educated people to perform more white collar jobs than the private sector, and these characteristics are positively correlated with the likelihood of engaging in prosocial activities.

\subsection{Longitudinal sample}

In this section, we exploit the panel structure of the survey to form a subsample of 1,800 individuals that we can observe both in the work and retirement stage. By focusing on this group, that we refer to as the longitudinal sample, we are able to gain further insight as to 
whether the similarity we see in the results in Table 3 between the two cross-sections of workers and retirees is genuine and is not due to a cohort or other effect. We first check whether this subsample is similar to the baseline sample of workers and retirees in terms of the public/private difference in prosociality. Reassuringly, in unreported regressions, we find the same pattern, both when they are working and when they are retired, as in the baseline samples, that is, there is a significant public sector premium, which disappears once we control for education and occupation.

We then pool the data and estimate a linear probability model of the likelihood of volunteering on dummy variables for whether an individual is or has been employed in the public sector and on whether he is retired, plus the interaction of the two. The results of this estimation are reported in column (1) of Table 6. We see that the likelihood of volunteering for workers in the private sector is $14.1 \%$ in this subsample, in line with the overall tendency we reported in Table 2 . Workers in the public sector are significantly more likely to volunteer by 4.4 percentage points, and there is also evidence of a retirement premium, as retired individuals in this subsample are more likely to volunteer by 10.8 percentage points. The interaction term is positive and insignificant, indicating that there is no differential increase in the propensity to volunteer across workers in the two sectors when they retire. In columns (2) and (3) of Table 6, we add country fixed effects and controls for education and occupation and see no difference in the estimated coefficients except for the fact that, as in the baseline sample, controlling for education and occupation eliminates the difference between public and private sector. Finally, in column (4), we add individual fixed effects to account for any individual-specific time-invariant characteristics and find that the pattern outlined above is robust.

In the introduction, we discussed how the approach of using current employees to identify differences between the private and public sector in terms of public service motivation is potentially subject to both positive and negative biases related to differences in working conditions and to differences between marginal and overall motivation. The fact that in this longitudinal analysis, we see a common shift in the prevalence of volunteering when

Table 6 Longitudinal analysis

\begin{tabular}{lcccc}
\hline & $\mathbf{( 1 )}$ & $\mathbf{( 2 )}$ & $\mathbf{( 3 )}$ & $\mathbf{( 4 )}$ \\
\hline Retired & $0.108^{* * *}$ & $0.108^{* * *}$ & $0.106^{* * *}$ & $0.108^{* * *}$ \\
& $(0.015)$ & $(0.015)$ & $(0.015)$ & $(0.015)$ \\
Public & $0.044^{* *}$ & $0.030^{*}$ & -0.01 & \\
& $(0.017)$ & $(0.018)$ & $(0.019)$ & 0.01 \\
Retired x Public & 0.01 & 0.01 & 0.02 & $(0.022)$ \\
& $(0.022)$ & $(0.022)$ & $(0.023)$ & $0.163^{* * *}$ \\
Constant & $0.141^{* * *}$ & $0.108^{* * *}$ & $0.253^{* * *}$ & $(0.006)$ \\
& $(0.012)$ & $(0.031)$ & $(0.09)$ & \\
Controls & & & Yes & Yes \\
Country FE & & Yes & & 3,600 \\
Individual FE & & 3,600 & 3,520 & 1,800 \\
\hline Observations & 1,800 & 1,760 & 0.06 \\
Individuals & 1,800 & 0.05 & 0.07 & \\
R squared & 0.02 & & &
\end{tabular}

Notes: Controls include education and occupation.

$*^{* *}\left[{ }^{* *}\right](*)$ denote significance at $1,[5],(10) \%$ level.

Standard errors clustered at the individual level are reported in parentheses. 
an individual transitions from employment to retirement suggests that these biases are either small or cancel each other out. This is consistent with the fact that we obtain a very similar picture when looking at the workers and at the retirees samples.

\section{Results by industry, occupation, tenure, age and country}

After having looked at the public sector as a whole, in this section, we conduct some subsample analysis, disaggregating the public sector into its main industries, looking separately at the most important professional groups, and exploring heterogeneity along the tenure, age, and country dimensions. We present this analysis only for the sample of retirees, where the sample size is larger and therefore subsamples do not get too small. In any case, the overall message is the same when repeating the analysis for the employees sample, with the few exceptions noted in the text.

\subsection{Industry}

So far we have looked at the public sector considered as a whole. We now focus in more detail at the different key industries of the sector. From Table 7, it emerges that the largest share of employment in the public sector is concentrated in "Public Administration and Defence", accounting for $26 \%$ of total employment. Another important component of the public sector is represented by what can be characterized as "caring" industries, that is, education (23\%) and health and social work (15\%). Something that is also evident in Table 7 is that, of course, the industrial composition of the private sector is very different, with a high concentration of workers in manufacturing (37\% of the private sector workforce), followed by wholesale and retail (12\%) and construction (11\%).

One might hypothesize that there may be differences in prosocial motivation across industries in the public sector itself. For instance, one might expect that individuals working in caring industries display higher prosocial inclination, as jobs in these industries offer more opportunities for engagement in on-the-job prosocial activities. To investigate this, we split the public sector into four groups: education, health and social work, public administration, and other (includes all other industries). We estimate our baseline

Table 7 Employment by industry and sector - retirees

\begin{tabular}{lccc}
\hline Industry & Private & Public & Total \\
\hline Agriculture, hunting & 6.7 & 0.9 & 4.7 \\
Mining and quarrying & 2.1 & 0.6 & 1.6 \\
Manufacturing & 36.6 & 2.6 & 25.0 \\
Electricity, gas and water supply & 1.6 & 3.5 & 2.2 \\
Construction & 10.6 & 2.0 & 7.7 \\
Wholesale and retail & 11.7 & 1.7 & 8.3 \\
Hotels and restaurant & 3.0 & 0.6 & 2.2 \\
Transport, storage and communication & 4.9 & 11.1 & 7.0 \\
Financial intermediation & 4.6 & 1.9 & 3.7 \\
Real estate, renting & 4.0 & 3.4 & 3.8 \\
Public administration and defence & 0.5 & 25.5 & 9.0 \\
Education & 1.4 & 22.8 & 8.7 \\
Health and social work & 3.7 & 15.2 & 7.6 \\
Other community, social and personal services & 8.7 & 8.2 & 8.5 \\
\hline Total & 100 & 100 & 100 \\
\hline
\end{tabular}


Table 8 Logit regressions - industry

\begin{tabular}{lcc}
\hline & \multicolumn{2}{c}{ Retirees } \\
\cline { 2 - 3 } & $\mathbf{( 1 )}$ & $\mathbf{( 2 )}$ \\
\hline Education & $0.144^{* * *}$ & $0.052^{* *}$ \\
Health and social work & $(0.023)$ & $(0.022)$ \\
& $0.067^{* * *}$ & 0.017 \\
Public Administration & $(0.021)$ & $(0.018)$ \\
& $0.038^{* *}$ & -0.014 \\
Other & $(0.018)$ & $(0.015)$ \\
& $0.033^{* *}$ & 0.012 \\
Controls & $(0.015)$ & $(0.014)$ \\
$N$ & No & Yes \\
\hline
\end{tabular}

Note: ${ }^{* *}\left[{ }^{* *}\right](*)$ denote significance at $1,[5],(10) \%$ level.

All the entries are average marginal effects.

logit regression by adding a set of dummies for whether a public sector retiree reports to have been last employed in a job in each of these four groups. We report the results of this estimation with and without controls in Table 8. In the unconditional regression, we see a positive association between voluntary work and each of the four categories, with the marginal effects standing at $14.4 \%, 6.7 \%, 3.8 \%$ and $3.3 \%$ for education, health, public administration and other, respectively. Note that the comparison group here is individuals who have retired from jobs in the private sector. When we add the various controls, as we did in Table 3, the marginal effect of education shrinks to $5.2 \%$ but remains significant; that of health and social work falls to $1.7 \%$ and is insignificant, whereas the marginal effects of public administration and other industries are also insignificant.

To summarize, this analysis identifies a particular group of public sector workers, those employed in education, that display a much higher propensity to volunteer compared to workers in the private sector. Moreover, this difference remains significant even after controlling for personal characteristics. On the other hand, workers in public administration or in other parts of the public sector are indistinguishable in terms of motivation from comparable workers in the private sector.

It is worth noticing that in the employees sample, the coefficient for education is close to zero and insignificant when we add controls, as are the coefficients for the other industry dummies. This pattern could be an indication that teachers have indeed higher motivation, but, while at work, they also have the opportunity to behave altruistically on the job and, thus, do not appear particularly prosocial out of working hours. After retirement, as they do not have this opportunity anymore, their motivation gets expressed through volunteering.

\subsection{Occupation}

One could also expect prosocial motivation in the public sector to be heterogeneous across occupations. It could be the case, for instance, that due to the compression that characterizes the wage structure in the public sector (Borjas 2002), in high-skill occupations, only highly prosocial workers are attracted to the public sector, while in low-skill occupations, we might even expect "negative" selection in terms of prosocial motivation, with people willing to "bend the rules" in order to get the relatively lucrative jobs offered 
in the public sector. It is also of specific interest to look at categories like managers or professionals separately, as they have a leadership role and a capacity to exert great influence in the delivery of public services. For these reasons, in Table 9 we estimate Equation 1 for three different occupational groups separately. The first group, "Managers and Professionals" combines the categories "Managers" and "Professionals" from Table 2. The second group includes "Technicians or Associate Professionals" and "Clerks", while the "Other" includes all the remaining occupational categories ${ }^{10}$.

The results for managers and professionals, columns (1) and (2), and for the "Other" category, columns (5) and (6), show a positive and significant differential that becomes insignificant after adding controls, consistent with the pattern observed for the sample as a whole. For technicians and clerks, columns (3) and (4), coefficients are closer to zero and never significant. Thus, all in all, the analysis by occupation shows that the result for the whole sample is not due to a mixing of positive selection at the top of the skill distribution combined with negative selection at the bottom, but is rather homogeneous across broad occupational categories.

\subsection{Tenure}

It may well be the case that prosocial motivation is not a fixed characteristic, but changes in the progress of one's career. In particular, it has been argued that phenomena like mission-drift or mission-shift may lead workers in the public sector who are initially very motivated to become disillusioned in the course of their career (Buurman et al. 2012). Conversely, an individual who is initially relatively unmotivated by social causes may become more sensitive to these issues through the process of socialization to the prosocial culture that permeates certain public sector institutions.

To investigate these issues, we next examine whether there are differences in prosocial motivation across former public sector workers depending on their job tenure. The idea is that, if mission-drift is a major issue, then longer tenure in the public sector may be associated with lower prosociality. If, instead, socialization is the main driving force, the opposite would be true. We focus on the subsample of retirees from the public sector and estimate the impact of having a tenure above the median on our measure of prosociality. In our sample, the median number of years spent on a public sector job before retirement is 30 years.

In Table 10 we report the results of a logit regression with and without the usual controls. In the unconditional regression (column 1), we find a significant 5.4 percentage point prosocial motivation premium in the subgroup with longer tenure. When we add controls, this premium remains positive but decreases in size and is statistically

Table 9 Logit regressions - occupation

\begin{tabular}{|c|c|c|c|c|c|c|}
\hline \multicolumn{7}{|c|}{ Retirees } \\
\hline & \multicolumn{2}{|c|}{ Managers \& professionals } & \multicolumn{2}{|c|}{ Technicians \& clerks } & \multicolumn{2}{|c|}{ Other } \\
\hline & (1) & (2) & (3) & (4) & (5) & (6) \\
\hline \multirow[t]{2}{*}{ Public } & $0.055^{* *}$ & 0.031 & 0.008 & 0.000 & $0.033^{* * *}$ & 0.014 \\
\hline & $(0.025)$ & $(0.026)$ & $(0.019)$ & $(0.018)$ & $(0.012)$ & $(0.011)$ \\
\hline Controls & No & Yes & No & Yes & No & Yes \\
\hline N & 3728 & 3728 & 5680 & 5680 & 9948 & 9948 \\
\hline
\end{tabular}

Note: ${ }^{* *}[* *](*)$ denote significance at $1,[5],(10) \%$ level. The entries are average marginal effects; standard errors are reported in parentheses. 
Table 10 Logit regressions - by tenure

\begin{tabular}{lcc}
\hline & \multicolumn{2}{c}{ Retirees } \\
\cline { 2 - 3 } & $\mathbf{( 1 )}$ & $\mathbf{( 2 )}$ \\
\hline Long Tenure & $0.054^{* * *}$ & 0.025 \\
& $(0.017)$ & $(0.017)$ \\
\hline Controls & No & Yes \\
$\mathrm{N}$ & 6362 & 6362 \\
\hline
\end{tabular}

Notes: All columns include country and survey wave dummies.

Long Tenure is a dummy for having more than 30 years job tenure in the public sector.

The entries are average marginal effects; standard errors are reported in parentheses.

*** denotes significance at $1 \%$ level.

insignificant. Thus, we do not find evidence that longer tenure in the public sector leads to depletion of public service motivation. If anything, there is some weak evidence of prosociality even increasing with tenure.

An obvious limitation of this analysis is that we only know the sector of a retiree's last job. Therefore, it could be that some individuals, who we classify as having short public sector tenure, may have switched jobs within the sector near their retirement, so in fact they have had a long career in the sector. Nevertheless, we believe it is informative to split the data in this way.

\subsection{Age group}

In this section, we check whether there is a cohort effect or time trend in the crosssectoral difference in prosociality. In particular, one might postulate that we are more likely to find differences in prosociality across sectors in the latter cohorts of workers who started entering the labor force in the early $60 \mathrm{~s}$, a period of rapid economic development for many of the countries in our sample - as opposed to the earlier cohorts who, on average, made career choices just after the second World War. This could be the case because, with a rapidly expanding private sector providing lots of opportunities, only very motivated people would choose to pursue a career in the public sector. To check whether this is indeed the case, we examine whether the results obtained so far are robust to splitting the sample into two groups by date of birth: those born before 1940 and those born after. This split divides the sample into roughly two equally sized subgroups.

Table 11 shows unconditional and conditional marginal effects of public sector experience for the two age groups. The pattern of the coefficients we obtain are very similar across the two groups and very similar to those obtained for the whole sample in Table 3, both in terms of magnitude and statistical significance. This provides some confidence that the results reported above are not driven by one particular cohort of workers in our sample.

\subsection{Country}

So far, we have conducted the analysis on the pooled sample from the 12 countries under study. It could be the case that the lack of difference in prosociality that we find in the conditional regressions is due to the fact that we mix countries where public sector workers are more prosocially motivated than their private sector counterparts with countries where public sector workers are more antisocial, for instance, because public sector 
Table 11 Logit regressions - by age group

\begin{tabular}{|c|c|c|c|c|}
\hline \multicolumn{5}{|c|}{ Retirees } \\
\hline & \multicolumn{2}{|c|}{ Born before 1940} & \multicolumn{2}{|c|}{ Born after 1940} \\
\hline & (1) & (2) & (3) & (4) \\
\hline \multirow[t]{2}{*}{ Public } & $0.057^{* * *}$ & 0.015 & $0.063^{* * *}$ & 0.008 \\
\hline & $(0.012)$ & $(0.011)$ & $(0.016)$ & $(0.015)$ \\
\hline Controls & No & Yes & No & Yes \\
\hline N & 9203 & 9203 & 10275 & 10275 \\
\hline
\end{tabular}

employment is a way to extract rents and bribes from the rest of society. To assess whether the previous analysis masks such types of cross-country heterogeneity, in this section, we conduct the analysis for each of the 12 countries in our sample separately, with the caveat that, as evident from Table 1, sample sizes can become rather small.

In Table 12, we report both the unconditional and conditional marginal effect of having public sector experience. The unconditional marginal effects indicate statistically significant differences in prosociality across workers in the two sectors in all but 4 countries (Sweden, Denmark, Greece and Portugal) ${ }^{11}$. Among the 8 countries where the marginal effect is significant, we find substantial heterogeneity in the public-private difference in

Table 12 Country-specific logit regressions

\begin{tabular}{|c|c|c|}
\hline & \multicolumn{2}{|c|}{ Retirees } \\
\hline & $\begin{array}{l}\text { Unconditional } \\
\text { marginal effect }\end{array}$ & $\begin{array}{c}\text { Conditional } \\
\text { marginal effect }\end{array}$ \\
\hline \multirow[t]{2}{*}{ Austria } & $0.077^{* * *}$ & $0.032^{* *}$ \\
\hline & $(0.017)$ & $(0.016)$ \\
\hline \multirow[t]{2}{*}{ Germany } & $0.079^{* * *}$ & 0.04 \\
\hline & $(0.026)$ & $(0.025)$ \\
\hline \multirow[t]{2}{*}{ Sweden } & 0.03 & 0.01 \\
\hline & $(0.021)$ & $(0.023)$ \\
\hline \multirow[t]{2}{*}{ Netherlands } & $0.091^{* * *}$ & $0.048^{*}$ \\
\hline & $(0.027)$ & $(0.028)$ \\
\hline \multirow[t]{2}{*}{ Spain } & $0.046^{* *}$ & 0.02 \\
\hline & (0.019) & (0.018) \\
\hline \multirow[t]{2}{*}{ Italy } & $0.072^{* * *}$ & -0.01 \\
\hline & $(0.026)$ & $(0.023)$ \\
\hline \multirow[t]{2}{*}{ France } & $0.054^{* *}$ & 0.00 \\
\hline & $(0.024)$ & $(0.023)$ \\
\hline \multirow[t]{2}{*}{ Denmark } & 0.04 & 0.02 \\
\hline & $(0.024)$ & $(0.026)$ \\
\hline \multirow[t]{2}{*}{ Greece } & 0.01 & 0.01 \\
\hline & $(0.014)$ & $(0.023)$ \\
\hline \multirow[t]{2}{*}{ Switzerland } & $0.047^{*}$ & 0.01 \\
\hline & $(0.026)$ & $(0.025)$ \\
\hline \multirow[t]{2}{*}{ Belgium } & $0.089^{* * *}$ & 0.01 \\
\hline & $(0.022)$ & $(0.023)$ \\
\hline \multirow[t]{2}{*}{ Portugal } & 0.04 & -0.02 \\
\hline & $(0.033)$ & $(0.025)$ \\
\hline
\end{tabular}

Notes: ${ }^{* *}[* *](*)$ denote significance at $1,[5],(10) \%$ level. 
prosocial motivation. In particular, the Netherlands exhibits the largest difference $(9.1$ percentage points), with Spain exhibiting the smallest (4.6 percentage points). The ranking would of course be very different if we considered the relative difference, given the high heterogeneity in prosocial motivation across countries documented in Table 1. Once we control for the various individual characteristics, the marginal effects shrink dramatically and become statistically insignificant in all but two countries, Austria and the Netherlands, where the difference remains at $3.2 \%$ and $4.8 \%$, respectively. Among the rest of the countries, in Germany, the difference across sectors also remains sizeable at 3.6\% but is not precisely estimated, while in the rest of the cases, the marginal effect is even numerically very close to zero.

Thus, this country-specific analysis is overall consistent with the picture emerging when we consider the whole sample, indicating that the lack of a differential in motivation between public and private sector workers is not due to a mixture of countries with positively selected and negatively selected public employees in terms of prosocial motivation.

\section{Discussion and conclusion}

In this paper, we investigate empirically whether public and private sector employees differ in terms of prosocial motivation using a large sample of elderly and retired workers from 12 European countries. We find significant differences in prosocial motivation across the two sectors, but, with the exception of the education sector, these are explained by differences in (former) workers' education and occupation.

An important limitation of this analysis is that, like most of the literature, we use a self-reported proxy for public sector motivation, namely volunteering. The survey also contains information about another measure of social preferences, i.e., whether most people can be trusted or not. Looking at this measure (see the working paper version, Tonin and Vlassopoulos 2014), we do find similar results, with retirees from the public sector displaying more trust in unconditional regressions but no difference between the public and private sector once controls are included (for employees, the difference is never significant $)^{12}$.

Another limitation already mentioned above is that, with the data at hand, it is not possible to fully assess whether the results are due to the fact that selection of prosocially motivated individuals into public sector jobs does not take place or whether selection is active at the recruitment stage, but prosocial motivation dissipates over time and thus is no longer present at later stages of the career. Our analysis of heterogeneity along the tenure dimension suggests that this may not be the case, but, as mentioned in Section 5.3, there are some limitations to this analysis. So, potentially, this could explain the difference between our results and the ones discussed in the literature review, where a significant difference between the two sectors is usually found. Other explanations could be related to the fact that most of these studies do not control for occupation, a variable we have shown in Section 4.2 to be important in explaining differences in prosocial motivation across sectors. In addition, some of these studies only consider a subgroup of workers (workers in the caring sector in Gregg et al. 2011; teachers in Dohmen and Falk 2010) or find a difference only for a subset of the population, as in Dur and Zoutenbier (2014), where altruism needs to be combined with confidence in political parties to increase the likelihood of working in the public sector. Likewise, in our analysis, when we split the public sector into its main components in Section 5.1, we find that public sector former 
workers in education are more prosocial than comparable workers both in the public and the private sector. Moreover, as reported in the country-specific analysis in Section 5.5, the difference in prosociality persists in some countries even after adding controls.

From a policy perspective, if the public sector fails to select workers with public service motivation, then recruitment policies would need to be modified. Recent evidence (Dal Bo et al. 2013; Ashraf et al. 2014) shows, for instance, that offering higher compensation or career prospects is not incompatible with being able to attract pro-socially minded workers, and further research, particularly in advanced economies, is certainly needed. On the other hand, if it is the case that the public sector attracts prosocial workers, but this attitude dissipates over time, then this would have implications, for instance, for the design of career paths. Namely, closely linking career progression to tenure, as is common in the public sector in many countries, would effectively mean selecting people lacking in public service motivation for leadership positions. Moreover, the public sector workforce in many OECD countries is ageing at an even faster pace than the rest of society due to the rapid expansion of the workforce from the 1970s until the mid 1980s followed by stabilization and hiring freezes in the 1980s and 1990s (Pilichowski et al. 2007). If public service motivation decreases with tenure, it will then progressively become scarcer in the public sector, with implications for the delivery of public services.

\section{Endnotes}

${ }^{1}$ For a survey of the extensive public administration literature on public service motivation, see Perry et al. (2010).

${ }^{2}$ This methodology has been used extensively in the literature that we review in the next section, using measures like unpaid overtime, charitable donations, volunteering, blood donations, or participation in nonpolitical civic affairs.

${ }^{3}$ This paper uses data from SHARE wave 4 release 1.1.1, as of March 28th 2013 or SHARE wave 1 and 2 release 2.5.0, as of May 24th 2011 or SHARELIFE release 1, as of November 24th 2010. The SHARE data collection has been primarily funded by the European Commission through the 5th Framework Programme (project QLK6-CT-2001-00360 in the thematic programme Quality of Life), through the 6th Framework Programme (projects SHARE-I3, RII-CT-2006-062193, COMPARE, CIT5-CT-2005-028857, and SHARELIFE, CIT4-CT-2006-028812) and through the 7th Framework Programme (SHARE-PREP, No. 211909, SHARE-LEAP, No. 227822 and SHARE M4, No. 261982). Additional funding from the U.S. National Institute on Aging (U01 AG09740-13S2, P01 AG005842, P01 AG08291, P30 AG12815, R21 AG025169, Y1-AG-4553-01, IAG BSR06-11 and OGHA 04-064) and the German Ministry of Education and Research as well as from various national sources is gratefully acknowledged (see www.share-project.org for a full list of funding institutions).

${ }^{4}$ We exclude five Eastern European countries for which the role of the public sector during socialism was very different from Western Europe. We also exclude Israel and Ireland, both of which have a very small sample size. We cannot use wave 3 of SHARE as it does not contain the question on volunteering.

${ }^{5}$ In wave 4 , this question refers to the previous year.

${ }^{6}$ In the Appendix, we report the survey questions behind the main variables used in the analysis. There is a significant number of individuals with missing values for the categorical variable on settlement type. So as not to drop these individuals from the analysis, we assign them to a separate category, "missing".

${ }^{7}$ For workers, there are statistically significant differences across the two sectors in all of the characteristics in Table 2, with the exception of age, couple, limited activities, time pressure and adequacy of job salary. For retirees, the only exception is gender. 
${ }^{8}$ Results are very similar when we use a linear probability model.

${ }^{9}$ Adding to these regressions month of interview as a control for possible seasonal variation in the likelihood to volunteer does not change the signs, significance or even the size of the coefficients on the public sector that we report on Table 3.

${ }^{10}$ Notice that we do not consider the category "Armed forces", as this category contains only a few individuals who report to have worked in the private sector.

${ }^{11}$ Note that of these four countries, two have low percentages of volunteering activity (Greece and Portugal), while the other two (Sweden and Denmark) have relatively large percentages of retirees with volunteering activity (over 20\%) and very large public sectors.

${ }^{12}$ In the working paper version, we also investigate whether employees in the public and private sectors differ along other dimensions, such as, risk attitudes, political views, and life satisfaction. We find some evidence of public sector employees being more risk averse, more left leaning in terms of their political preferences, and more satisfied with their job and life.

\section{Appendix}

\section{Main Variables}

Here we report the survey questions behind the main variables used in the analysis.

Prosociality: "Have you done any of these activities in the last month? [For Wave 4: Which of the activities listed on this card - if any - have you done in the past twelve months?] Done voluntary or charity work. [...]"

Health status: "For the past six months at least, to what extent have you been limited because of a health problem in activities people usually do? [Severely limited/ Limited, but not severely/ Not limited]"

Income: this variable is generated by SHARE through a suitable aggregation of the individual and household income components collected in the survey. We use the version including imputations. Details about the methodology are available on the survey website. Club:"Have you done any of these activities in the last month? [For Wave 4: Which of the activities listed on this card - if any - have you done in the past twelve months?] [...] Gone to a sport, social or other kind of club. [...]"

Time Pressure:"I am under constant time pressure due to a heavy workload. (Would you say you strongly agree, agree, disagree or strongly disagree?)"

Job Salary Adequate:"Considering all my efforts and achievements, my salary is adequate. (Would you say you strongly agree, agree, disagree or strongly disagree?)"

Competing interests

The IZA Journal of Labor Economics is committed to the IZA Guiding Principles of Research Integrity. The authors declare that they have observed these principles.

\section{Acknowledgments}

We thank the Editor, Pierre Cahuc, two anonymous referees, Alessandro Bucciol, Robert Dur, Dimitris Georgarakos, Luigi Siciliani for insightful comments and participants at the Workshop on Economics of Nonprofits, Governments, Organizations, PEUK 2014, Conference on the Impact of Institutions and Regulation on Public Services, ISNIE 2013, ZEW Public Finance Conference and various seminars for helpful comments.

Responsible editor: Pierre Cahuc.

\section{Author details}

${ }^{1}$ Economics Department, Social Sciences, University of Southampton, Southampton SO17 1BJ, UK. ${ }^{2}$ CESifo, Munich, Germany. ${ }^{3}$ UniCredit Foscolo Fellow, CEU, Budapest, Hungary. ${ }^{4}$ IZA, Bonn, Germany. 


\section{References}

Ashraf N, Bandiera O, Lee SS (2014) Do-gooders and Go-getters: career incentives, selection, and performance in public service delivery, HBS Working Paper

Bandiera O, Prat A, Valletti T (2009) Active and passive waste in government spending: evidence from a policy experiment. Am Econ Rev 99(4):1278-1308

Banuri S, Keefer P (2013) Intrinsic motivation, effort and the call to public service. World Bank Policy Research Working Paper 6729

Besley T, Ghatak M (2003) Incentives, choice, and accountability in the provision of public services. Oxford. Rev. Econ. Policy 19(2):235-249

Besley, T, Ghatak M (2005) Competition and incentives with motivated agents. Am Econ Rev 95(3):616-636

Borjas GJ (2002) The wage structure and the sorting of workers into the public sector, NBER working paper, No 9313.

Brewer GA (2003) Building social capital: civic attitudes and behavior of public servants. J Public Adm Res Theory 13(1):5-26

Brunello G, Fort M, Weber G (2009) Changes in compulsory schooling, education and the distribution of wages in Europe. Econ J 119(536):516-539

Buurman M, Delfgaauw J, Dur R, van den Bossche S (2012) Public sector employees: risk averse and altruistic? J Econ Behav Organ 83(3):279-291

Christelis D, Jappelli T, Padula M (2010) Cognitive abilities and portfolio choice. Eur Econ Rev 54(1):18-38

Christelis D, Georgarakos D, Haliassos M (2013) Differences in portfolios across countries: economic environment versus household characteristics. Rev Econ Stat 95(1):220-236

Cowley E, Smith S (2014) Motivation and mission in the public sector: evidence from the World Values Survey. Theory and Decision 76(2):241-263

Crespo L, Mira P (2014) Caregiving to elderly Parents and employment status of European mature women. Rev Econ Stat 96(4):693-709. DOI: 10.1162/REST_a_00426

Dal Bo E (2006) Regulatory capture: a review. Oxford Rev Econ Policy 22(2):203-225

Dal Bo E, Finan F, Rossi M (2013) Strengthening state capabilities: the role of financial incentives in the call to public service. Q J Econ 128(3):1169-1218

Delfgaauw J, Dur R (2008) Incentives and workers' motivation in the public sector. Econ J 118(525):171-191

Dixit A (2002) Incentives and organizations in the public sector: an interpretative review. J Hum Resour 37(4):696-727

Dohmen T, Falk A (2010) You get what you pay for: incentives and selection in the education system. Econ J 120(546):F256-F271

Dur R, Zoutenbier R (2012) Intrinsic motivation of public sector employees: evidence for Germany, Tinbergen Institute Discussion Paper 2012-135/1. German Econ Rev. DOl: 10.1111/geer.12056

Dur, R, Zoutenbier R (2014) Working for a good cause. Public Adm Rev 74(2):144-155

Francois P (2000) 'Public service motivation' as an argument for government provision. J Public Econ 78(3):275-299

Francois P, Vlassopoulos M (2008) Pro-social motivation and the delivery of social services. CESifo Econ Stud 54(1):22-54

Gregg P, Grout PA, Ratcliffe A, Smith S, Windmeijer F (2011) How important is pro-social behaviour in the delivery of public services? J Public Econ 95(7-8):758-766

Hank K, Erlinghagen M (2010) Dynamics of volunteering in older Europeans. Gerontologist 50(2):170-178

Hanna R, Wang SY (2013) Dishonesty and selection into public service, National Bureau of Economic Research WP No. 19649

Houston DJ (2006) Walking the walk of public service motivation: public employees and charitable gifts of time, blood, and money. J Public Adm Res Theory 16(1):67-86

Jovanovic B (1979) Job matching and the theory of turnover. J Pol Econ 87(5):972-990

Kesternich I, Siflinger B, Smith JP, Winter JK (2012) The effects of World War II on economic and health outcomes across Europe. Rev Econ Stat 96(1):103-118

Lagarde M, Blaauw D (2013) Pro-social preferences and self-selection into rural jobs: evidence from South African nurses, mimeo

Lee Y (2012) Behavioral implications of public service motivation: volunteering by public and nonprofit employees. Am Rev Public Adm 42(1):104-121

Mazzonna F, Peracchi F (2012) Ageing, cognitive abilities and retirement. Eur Econ Rev 56(4):691-710

OECD (2011) Government at a Glance 2011. OECD Publishing, Paris

Perry JL, Hondeghem A, Wise LR (2010) Revisiting the motivational bases of public service: twenty years of research and an agenda for the future. Public Adm Rev 70(5):681-690

Pilichowski E, Arnould E, Thrkisch E (2007) Ageing and the public sector: challenges for financial and human resources. OECD J Budgeting 7(4):1-40

Rohwedder S, Willis RJ (2010) Mental retirement. J Econ Perspect 24(1):119-138

Rotolo T, Wilson J (2006) Employment sector and volunteering: the contribution of nonprofit and public sector workers to the volunteer labor force. Sociol Q 47(1):21-40

Svensson J (2005) Eight questions about corruption. J Econ Perspect 19(3):19-42

Tonin M, Vlassopoulos M (2014) Are public sector workers different? Cross-European evidence from elderly workers and retirees, IZA Discussion Paper No. 8238 